\title{
The role of disposition to critical thinking in digital game-based learning
}

\author{
Manuel Gentile ${ }^{1}$, Giuseppe Città ${ }^{1}$, Salvatore Perna ${ }^{1}$, \\ Alessandro Signa ${ }^{1}$, Valentina Dal Grande ${ }^{1}$, Simona Ottaviano ${ }^{1}$, \\ Dario La Guardia $^{1}$, and Mario Allegra ${ }^{1}$ \\ ${ }^{1}$ Institute for Educational Technology \\ National Research Council of Italy, Palermo, Italy \\ \{manuel.gentile, giuseppe.citta, salvatore.perna, alessandro.signa, valentina.dalgrande, \\ simona.ottaviano, dario.laguardia, mario.allegra \}@itd.cnr.it
}

\begin{abstract}
The relationship between the development of 21st-century skills and game-based learning is a field to explore. Among the 21-st century skills, critical thinking is one of the most analyzed skills. This study aims to deepen the relationship between learning and disposition to critical thinking (DCT) in the context of Serious Games (SGs). In particular, starting from the evidence of previous work, that highlighted a positive effect of the DCT on game performance, this study analyzes how the DCT also affects the explicit learning gained by the players. This work highlights that the DCT has a crucial role in explicit knowledge acquisition and how the improvement of game performance is a direct consequence of DCT through a path analysis methodology.
\end{abstract}

Keywords: Disposition to Critical Thinking, Explicit Knowledge, Serious Games, 21st-century skills

\section{Introduction}

Game-based learning (GBL) is an approach through which different specific problem scenarios can be arranged in a play context $[1,2]$. It specifically refers to the use of computer games with educational value or software application that exploit games for enhancing learning within various domains [3, 4]. Sustainers of game-based learning claim that, through this approach, students can improve knowledge, and enhance thinking skills because they have to cope with immersive and realistic problem-solving settings.

Within this framework, Serious Games (SGs) are promoted as an excellent tool for supporting both formal and non-formal learning since they are often closer simulations of real-life experiences [5-8]. SGs are used to enhance learning at different ages and in several branches of knowledge [912], to involve players in activities and tasks aimed at the improvement of knowledge and thinking skills [13], and to repeatedly recall learning experiences engagingly [14].

Various research and review studies have been carried out to investigate the effectiveness and positive effects of GBL on enhancing players' knowledge $[9,15]$. Nevertheless, no agreement has been reached either on whether such benefits exist $[9,16]$ or, if they do, what they would affect (cognitive skills, knowledge contents or players' behavior). Such a situation reveals a worrying distance between the current definitions of SGs and what these games allow to foster and enhance.

Moreover, the current state of affairs [7] allows us to infer very little about how SGs affect and support the development of the so-called 21st-century skills [17]. 
The expression "21st-century skills" indicates those skills that human beings need to expertly possess to be a successful worker, a good citizen and to fully realize them as persons in a temporal context (the 21 st century) whose traits require new and adequate behaviors and abilities. In the literature, different definitions of " 21 st-century skills" have been given [17]. Nevertheless, three sets of skills, consistent with the core 21 st-century central themes, can be distinguished: learning and creative innovation skills; information, media, and technology skills; life and career skills.

As regards the learning and innovation skills, critical thinking and problem-solving are described as the "new basics of 21st-century learning" [18] and concern the ability to solve problems based on conscious manipulation of one's reasoning paths and knowledge contents. The second set of skills concern with the basics of good communication and collaboration strategies with and/or without digital tools to promote learning together. Creativity and innovation skills have to do with the requests of innovative solutions to the challenges raised by the 21 st century.

According to Qian et al. [7], within the intersection area of GBL and "21st-century skills", research works are in an initial phase of the investigation. Few studies analyze whether and how SGs can influence the development of students' 21 st-century skills, and all of them focus on problemsolving and critical thinking since, as mentioned, they are perceived as the necessary learning skills [19-23].

This paper aims to provide an original contribution to the studies concerning these basic learning skills focusing mainly on Critical Thinking. Despite its multiple and heterogeneous definitions, Critical Thinking can be defined as a pervasive characteristic of human beings. It makes them able to make judgments based on analysis, interpretation, evaluation, and inference. Thanks to their critical thinking skills, humans can clarify and analyze the meaning of arguments, evaluate evidence, judge whether a conclusion can follow from certain premises, justify one or more conclusions based on certain premises. In the context of the Delphi Project [24], Critical Thinking has been defined as the ability to make decisions through valid reasoning that pragmatically "manages" the conceptual, procedural, logical and contextual components underlying the decision-making processes.

In this perspective, it emerges that the analysis of Critical Thinking can be carried out on the basis of two different but mutually related approaches. It can be analyzed both in terms of capacity and disposition [25]: on the one hand as a process of elaboration of valid reasoning, on the other, as the propensity that every cognizer has in implementing such processes. Just referring to the latter, Glaser [26] describes the disposition to critical thinking (DCT) as "an attitude of being disposed to consider thoughtfully problems and subjects that come within the range of one's experiences." Kiliç et al. [27] suggest that disposition is the marker of critical thinking, while Paul et al. [28] argue that it is "the basis of strong sense of critical thinking." From this point of view, individuals with a lowlevel of disposition are not interested in complex questions, tend to look for different solutions for problems and often struggle to solve problems [27]. On the contrary, an individual with a high-level of disposition can resolve complex issues, diligent in searching for relevant information, rational in the choice of search criteria, rigorous in reasoning on a specific subject, determined in the face of challenges [24].

In a study conducted with 92 students, Gentile et al. [29] investigated how DCT influences the students' game-playing while using the serious game uManager. The study highlighted that DCT has an indirect impact on the users' in-game performances. In particular, the effect of DCT in respect to the in-game performance seems to be mediated by the number of information read by the student. Users with a high level of DCT tend to search and analyze the available information of the game more than users with a low level of DCT, and this more significant attention to information reflects the overall performance of the users.

Naturally, it is worth noticing that a reader could implicitly link this performance improvement to an increase in knowledge of the student. However, the previous study does not allow us to specify the nature of this learning when analyzed from an implicit and explicit learning perspective. For this reason, starting from the results of the previous research work [29], we want to verify if and how the DCT influences explicit learning. Also in this study, we limit our analysis to a specific portion of the 
knowledge domain stimulated by the game. In particular, we focus the knowledge related to understanding of customer preferences. To evaluate the explicit knowledge gained by the player, we defined a set of multiple-choice questions of different complexities that the students have to deal with during the game-playing after every simulation step.

In the following sections, we briefly describe the features of the serious game uManager (section 2 ) and then how we adapt its design to observe Critical Thinking in gaming (section 3). Thereafter, we describe the method of analysis (sample, measures, procedure, and data analyses) (section 4) and, finally, we report and discuss the results (section 5).

\section{2 uManager}

uManager is a PC-playable serious game designed to foster the entrepreneurial mindset in young students. According to Krueger [30], the entrepreneurial mindset is a high-level concept that involves a complex set of attitudes, skills, and competencies (e.g., decision making, problem-solving, and critical thinking). To this aim, uManager engages the students in a motivating and realistic learning path in which the user has to build and manage a resort village.

The game starts randomly assigning a specific customer typology as the target of the player. The goal of the player is to understand the needs of that customer typology and build up the village according, choosing which building to create and which services to provide in the resort, players also have to decide the best communication and marketing channels to promote the village.

The available customer categories are VIP, Senior, Low Cost, Young, and Family. Each category has different preferences concerning every aspect of the vacation in the resort and different spending power as well. Customer types are differently distributed in the market; each customer type has a different probability of being generated that is inversely proportional to the spending power of each customer type.

It is worth to specify that, despite the principal goal of the game is to satisfy the target customer typology, the village is open to all the customer categories. The resort will attract one or the other customer types based on the services offered. Players start the game with an initial amount of money and an empty terrain, including a beach. They can build the facilities in the available space of the map, hire employees, and manage entrance costs and salaries. In case of a financial deficit, players can ask for a loan, and they will repay the debt with interests in the next months. There is also a virtual assistant, which guides the player sending him messages about the available features of the game. uManager has a discrete-time progression; this means that the simulation starts once all the decisions are made. Each interval simulates a quarter of the year; during this time, customers visit the resort and spend their money enjoying the structures inside the village.

The player's choices affect several aspects of the business simulation in which the game is based. In Fig. 1, we have reported a schema highlighting how the main game mechanics impact the game variables. We represent the game mechanics as rectangles and the variables as circles. The dotted line identifies those mechanics which affect the cost variable, and the red line highlights those aspects we analyzed in this study. The player can directly monitor many of these variables by the available tables and graphs in the game. The game allows the player to view about ten linear graphs and see how the trend changes from quarter to quarter. The Quality graph, for example, indicates how much the target customer typology appreciates each service category offered in the village. The Visibility graph instead shows the marketing campaigns' efficacy regarding the village's notoriety to each customer typology. The player may also consult tables concerning financial recaps containing details about last quarter's costs and revenues. 


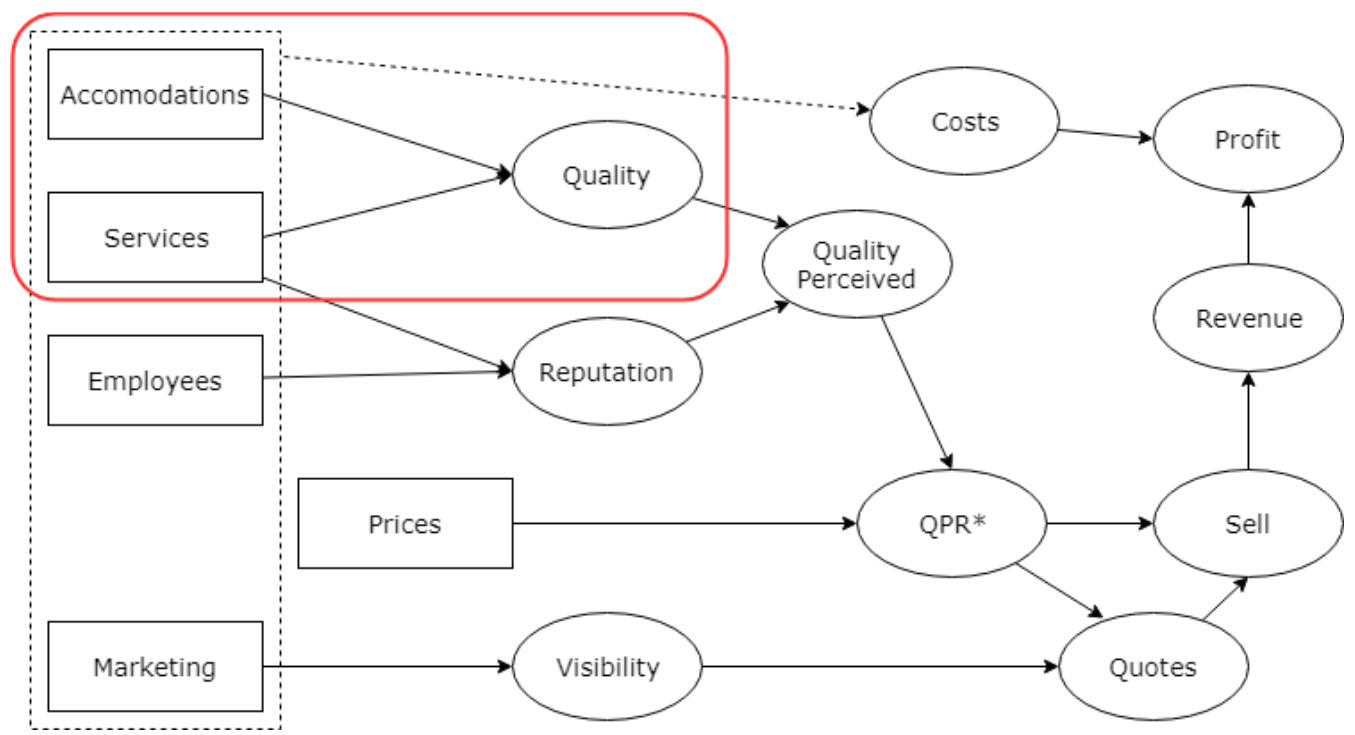

Figure 1. Causal network of game mechanics and game variables in uManager (* Quality Price Ratio).

During the game, the player has to understand and analyze the causal connections between his decisions and the game variables. For example, to get the best performance from each building in the village it is crucial to understand which are the employees that best fit for that purpose, it's also possible to modify the standard employees' salary to enhance their productivity. There is a huge variety of available employees, and the player can hire specific staff for each service sector, from bungalow's or hotel's cleaner to tennis teacher passing by the receptionist or the restaurant's chef. To obtain the maximum profit from employees' work it is essential to distinguish helpful roles and invest in them only. Employees do not affect the village's quality directly, but they produce an indirect and delayed effect through the reputation variable. The reputation variable is built from consumer agents who "live" in the village after they buy the entrance. The goodness of their experience inside the resort contributes to the village's reputation, which affects how other agents perceive the quality of the resort. This quality perception guides the customer who is about to evaluate the offering of a village for a vacation.

The quality perceived by each customer, which is defined by the total quality and the reputation, is evaluated together with the village entrance price to decide whether to buy the bundle or not. Players can modify the entrance price to give access to the village to the customers with less spending power or, otherwise, players can increase the prices and try to get more income from customers. Ultimately, to fully understand the game mechanics, the player has to activate high-level inferential processes which are hard to identify and evaluated automatically by the designers.

To comprehend how the critical thinking disposition affects the player's gaming capacity, we, therefore, limit our analysis focusing on the student's ability to choose services and accommodations preferred from the assigned customer typology.

\section{The design of uManager to analyze player's Critical Thinking}

In this section, we discuss how the design of uManager supports the observation of the processes that are at the base of critical thinking. In particular, we will highlight how we created the matching function among the customer typologies and the game asset, to have the possibility to give specific hints and create the conditions for observing critical thinking processes during the gameplay. Table 
1 shows the available game assets for each category of Services (Accommodation, Food, Sport, Relax).

Table 1. Assets' Categories Schema.

\begin{tabular}{c|c|c|c}
\hline Accommodation & Food Service & Sport & Relax \\
\hline Tent & Market & Soccer & Umbrella \\
\hline Camper & Self Service & Tennis & Massage \\
\hline Bungalow & Coffee Shop & Bowls & Yoga \\
\hline Duplex Bungalow & Restaurant & Swimming Pool & Seaview House \\
\hline Hotel & Organic Restaurant & Archery & Discotheque \\
\hline
\end{tabular}

For each service category, we identified a set of quality dimensions to categorize the game elements as well also the customer's preferences. For example, the accommodation service has been described according to the level of comfort they provide, the availability of external spaces, the level of cleaning service and room service from which they benefit, the level of privacy offered and the availability of other services (e.g., kitchen, laundry). By using the quality dimensions of each service category, it is possible to represent both the game assets and customer preferences as vectors in a multidimensional space and to calculate the distance between them. According to the values assigned to the quality dimensions, we provide a textual description for each customer cluster and asset. These descriptions allow the player to ground their decision-making processes not exclusively on his/her prior knowledge, providing explicit knowledge that has to be searched, read, and critically analyzed. Furthermore, because we want to avoid that they play without reading any of the information in the game, we need to lower as much as possible the chance of letting them play with customer target they believe to know, for this reason, we have chosen to assign the customer target in a randomly to every resort at the start of each game. This design approach, indeed, puts more emphasis on reading and analyzing the customer's information available in the game.

Table 2. Assets' Categories Schema.

\begin{tabular}{c|c|c|c|c|c}
\hline & Comfort & $\begin{array}{c}\text { External } \\
\text { Spaces }\end{array}$ & $\begin{array}{c}\text { Cleaning } \\
\text { Service }\end{array}$ & $\begin{array}{c}\text { Room } \\
\text { Service }\end{array}$ & Privacy \\
\hline Tent & -2 & 2 & -2 & -2 & 2 \\
\hline Camper & -1 & 2 & -2 & -1 & 1 \\
\hline Bungalow & 1 & 1 & 1 & 2 & 1 \\
\hline $\begin{array}{c}\text { Duplex } \\
\text { Bungalow }\end{array}$ & 1 & 1 & 1 & -1 & -2 \\
\hline Hotel & 2 & -2 & 2 & 2 & \\
\hline
\end{tabular}


As a concrete example of this design approach, we could consider one asset category (accommodations) and one customer cluster (VIPs). Table 2 shows the characterization of the various accommodations relative to the features identified for this category, while Table 3 shows the characterization of the VIPs customers' needs and beliefs relative to the same set of features.

Table 3. Preferences of customers related to accommodations.

\begin{tabular}{c|c|c|c|c|c}
\hline & Comfort & $\begin{array}{c}\text { External } \\
\text { Spaces }\end{array}$ & $\begin{array}{c}\text { Cleaning } \\
\text { Service }\end{array}$ & $\begin{array}{c}\text { Room } \\
\text { Service }\end{array}$ & Privacy \\
\hline VIP & 2 & -2 & 2 & 2 & -2 \\
\hline Senior & 2 & 1 & 1 & 2 & 0 \\
\hline Family & 0 & 0 & 2 & -1 & 2 \\
\hline Young & -2 & 2 & -2 & -2 & 2 \\
\hline Low cost & -1 & 1 & 0 & -2 & 2 \\
\hline
\end{tabular}

If we look at the vector characterizing the Hotel asset and the one characterizing the VIPs customer cluster, a clear correlation is easily spotted. The needs and beliefs of the VIPs customer cluster in regards to the accommodations strongly match the Hotel. To bring this correlation from the implicit to the explicit level, as discussed above, we created the following textual description: "VIPs choose very comfortable, high-quality service accommodations. Deeply jealous of their privacy, they prefer room service over both open spaces and ancillary services."; similarly, we formulated the following description for the Hotel: "Inside the Hotel, you can find the reception, some common areas, the refreshment zone and, certainly, rooms and apartments. These fulfill specific boundaries of refinement, elegance, and comfort and offer high-quality services (i.e., room service) to those who want to enjoy a vacation full of relaxing and privacy". We used bold-style in the above descriptions just to highlight the keywords that should stimulate the formulation of the associations through inference, while in the game the descriptions are reported as plain text to give the player the goal to infer the quality dimensions. These descriptions are available in the game, and the players can review them anytime by explicit clicking on the button "show more info" of each game asset or customer description.

\section{Methods}

A test-based training mode has been introduced in uManager to measure the explicit knowledge gained by the students during the game activity. At the end of each simulation cycle, the student had to deal with a set of three questions related to that portion of the game domain highlighted in the rectangle. Such a portion, as explained above, has to do with the identification of the quality dimensions that link the preferences of the consumer target assigned to the student with the services chosen by the player.

This method has been developed to allow students to verify their level of knowledge of the game dynamics, and, where necessary, to go later to recall the descriptions for a more careful reading of them. Students were not given positive or negative feedback about their answers to the questions. 


\subsection{Participants}

In this paper, we report a deep analysis of the results of a study conducted on five classes of two Sicilian secondary schools and presented in Gentile [29]. We analyze the results of 87 of the 92 students who took part in the trial. We removed one of these five cases because he/she did not complete the UF-EMI test. We eliminated the remaining four because the analysis of learning analytics revealed that the response times to their quizzes was near to nil, thus highlighting a not compliant behavior of students who, probability, systematically skipped these phases of the game.

\subsection{Procedures}

All participants were enrolled in a learning path of five meetings lasting about two hours each. During the first meeting, the UF-EMI test was administered to evaluate the students' critical thinking disposition, after which the game sessions began. The students had both the opportunity to resume the game interrupted in the previous session, and eventually start a new game, once assessed the impossibility of recovering the economic and financial situation of their village. The 87 students considered for this study played a total of 162 different games, with an average of about two games per student. At the end of the meetings, a de-briefing meeting was carried out to analyze together the progress of the activity and gather any feedback on the game itself.

\subsection{Measures}

\subsubsection{Critical thinking disposition}

To measure the students' DCT, we adopted the UF-EMI instrument. As described in Gentile [29], we adapted the 26 Likert-type items of the UF-EMI tool for the Italian language, using a backtranslation procedure to improve the quality of the translation.

The UF/EMI is a tool developed in 2003 by researchers at the University of Florida. In literature, it has often been used to measure DCT in business simulation [31]. In 2011, the test was replaced by another tool developed by the same researchers (the University of Florida Critical Thinking Inventory - UFCTI) to measure more accurately and reliably the critical thinking style and not the dispositon. Nevertheless, for the purposes of this research, the UF/EMI remains a valid and still usable tool.

UF-EMI measures DCT by means of three latent constructs able to clearly explain its dynamics:

- Cognitive Maturity refers to the student's awareness about the complexity of real problems, their prejudices, and those of others. It also has to do with the degree of openness that a learner has in comparison to points of view different from his/her own.

- Innovativeness accounts for a learner' predisposition to intellectual curiosity and research aimed at establishing the truth of the facts.

- Engagement reflects the disposition of a learner to seek opportunities and possibilities to elaborate reasoning anticipating situations that require a certain complexity of reasoning. This factor, moreover, regards also the confidence that learners put in their reasoning ability.

\subsubsection{In-game performance}

In this study, the game performance was measured using the resort Quality, that measures the player's ability to understand the targeted consumer preferences.

The overall resort quality is calculated as the average of the quality values achieved by the player for the different services category. For each typology of service, the game calculates a service quality 
considering the set of buildings/services added by the player. In particular, for each building/service, the preferences vector of the target customer is compared with the features vector of the building using the cosine function.

We adopted the cosine distance to get a similarity value that ranges from -1 to 1 and, thus, taking into account also the "indifference" of the customer for a particular building/service.

After, a sigmoid function is applied to the sum of all the distances, to scale this sum in the [0..1] range.

This quality value is updated continuously in the game after every single action taken by the player. For the aim of this study, we consider for each match the quality value obtained by the player at the end of the game, so that this value will be viewed as the final result of the student's performance.

\subsubsection{Gaming modality}

Starting from the results of the previous work [30], we assume that a high level of DCT leads the students to the exploration and critical analysis of the information provided by the game. To this end, a further game variable named InformativeAction was also taken into consideration. This measure, extracted from the game learning analytics, represents the number of the student's actions aimed at the information exploration.

Also for this variable, for the aim of this paper, we considered the final value for each game, the ratio of InformativeAction performed during the game.

\subsubsection{Explicit knowledge}

A collection of 275 multiple-choice questions were defined to measure the explicit knowledge gained by the students during the game activity. The questions, designed to stimulate the analysis of uManager descriptions and different possible inferences, were grouped into three different categories. Category 1 includes a total of 25 questions, each of which gives the player five answer choices. This type of question involves learners in knowledge recall tasks. It requires them to recall the information about characteristic factors (preferences, needs, economic availability) that determine the choices of the target customer about the different assets of the village.

Category number two collects questions relating to specific characteristics of an asset and asks the player to interpret them as possible causes or factors of influence that determine the choices of the target customer. Each question of this category gives the player three answer choices. The third category of questions investigates the knowledge acquired by the student on some characteristic traits of some specific game elements and his/her ability to extract it in a precise and punctual way.

We consider the ratio of correct responses given by the student during the game as an estimation of the gained knowledge. In Table 4, one example for each category is reported.

\subsection{Data Analysis}

To explore the direct dependencies between DCT, the InformativeAction report on the total number of actions performed, the ratio of CorrectAnswers to the questions and the final Quality of the resort managed by the student, we conducted a path analysis. Path analysis allows us to check the direct and indirect effect of DCT to all the observed variables.

All analyses were conducted in R [32] and, specifically, the path analyses were deployed using the version 0.6-1.1205 Lavaan package [33].

According to our hypothesis of causality between the variables involved (DCT $\Rightarrow$ InformativeAction $\Rightarrow$ CorrectAnswers $\Rightarrow$ Quality) we estimated all possible unidirectional paths to take into account both direct and indirect effect. Fig. 2 shows the basic model. 
Table 4. Descriptive statistics and intercorrelations among measured variables

\begin{tabular}{|c|c|}
\hline Variable & Questions and Answers \\
\hline Category 1 & $\begin{array}{l}\text { Which combination of features provided by a sports center is } \\
\text { crucial for the choice of your target customer? } \\
\text { - Possibility of practicing a sport suitable for all ages and } \\
\text { practiced by a wide range of people } \\
\text { - Presence of an instructor and sport practiced by few } \\
\text { people } \\
\text { - Possibility to practice sports suitable for all ages in high- } \\
\text { quality structures } \\
\text { - Possibility of practicing sports practiced by few people } \\
\text { that require a great physical effort } \\
\text { - Possibility to practice a sport that requires great physical } \\
\text { effort in high quality structures }\end{array}$ \\
\hline Category 2 & $\begin{array}{l}\text { What is the impact of the comfort factor in choosing } \\
\text { accommodation for your target client? } \\
\text { - Positive } \\
\text { - Neutral } \\
\text { - Negative }\end{array}$ \\
\hline Category 3 & $\begin{array}{l}\text { The presence of extra services in the Bio restaurant is } \\
\text { - Guaranteed } \\
\text { - Variable } \\
\text { - Absent }\end{array}$ \\
\hline
\end{tabular}

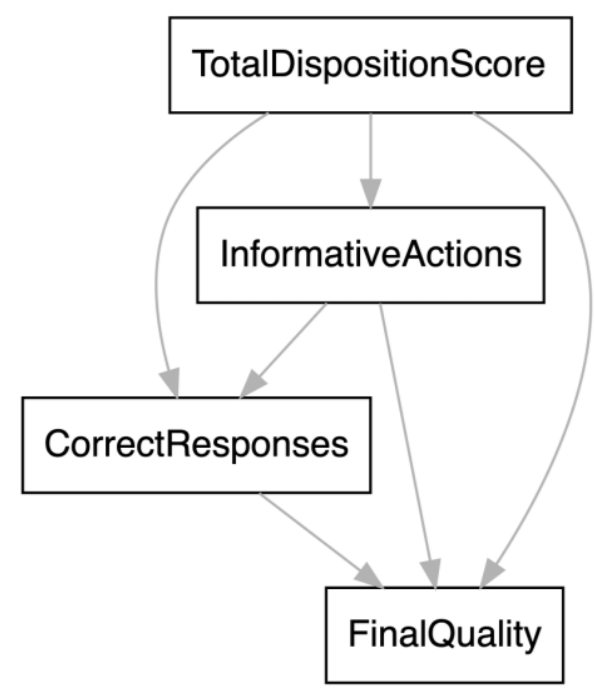

Figure 2. Path model with all the direct and indirect effects 


\section{Results}

\subsection{Descriptive statistics and correlation analyses}

Table 5 presents means, standard deviations, and intercorrelations between the considered variables. The descriptive analysis of the UF-EMI constructs is reported in Gentile et al. [29].

Table 5. Descriptive statistics and intercorrelations among measured variables

\begin{tabular}{c|c|c|c|c|c}
\hline Variable & M & SD & $\begin{array}{c}\text { Total } \\
\text { Disposition } \\
\text { Score }\end{array}$ & $\begin{array}{c}\text { Informative } \\
\text { Actions }\end{array}$ & $\begin{array}{c}\text { Correct } \\
\text { Responses }\end{array}$ \\
\hline $\begin{array}{c}\text { Total } \\
\text { Disposition Score }\end{array}$ & 91.17 & 9.04 & & & \\
\hline $\begin{array}{c}\text { Informative } \\
\text { Actions }\end{array}$ & 0.17 & 0.10 & 0.245 & & \\
\hline $\begin{array}{c}\text { Correct } \\
\text { Responses }\end{array}$ & 0.46 & 0.11 & 0.121 & 0.254 & \\
\hline Final Quality & 0.76 & 0.21 & 0.150 & 0.068 & 0.331 \\
\hline
\end{tabular}

\subsection{Path analyses}

To obtain the final model (Fig. 3) we trimmed the non-significant regression paths. According the generally accepted cutoff criteria [35], the final model achieved good fit on all indices (ratio of $\chi 2$ to $\mathrm{df}=1.079, \mathrm{RMSEA}=0.022, \mathrm{CFI}=0.994, \mathrm{TLI}=0.987$ ).

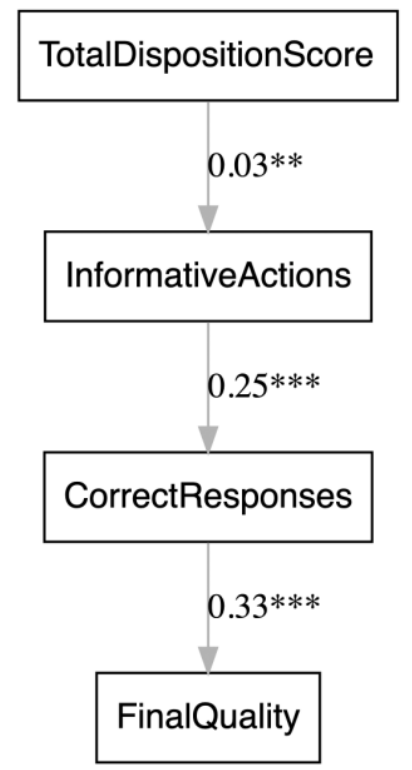

Figure 3. Final Path model 


\section{Conclusions}

In this paper, we have analyzed if and how DCT influences explicit learning and what is the relation with in-game performance.

First, according to the results of Gentile et al. [29], this work has shown that DCT affects the player's playing mode. In particular players with high DCT tend to perform a greater number (in percentage terms) of actions that have informative purposes. As a consequence, the ratio of InformativeActions influences the knowledge acquired by the player, measured through the questions administered within the game, and consequently on the total quality of the built village.

In our experimental design, the administration of the questions had the main function of verifying the knowledge acquired by the student thanks to the reading of the textual descriptions. In future works, by providing the student with real-time feedback on the correctness or mismatch of the given answers, it would be possible to analyze the role of a stimulus of the proposed questions. It would be possible to analyze if the repeated presentation of the learning contents and the linked and repeated practice on test trials have some positive effects on the number and accuracy of the students' subsequent readings.

Within this context, learning could be conceived as an incremental process that gradually grows across the study and test trials [35], and SG could be the ideal environment where observing this form of learning.

In the field of research this kind of development of learning is referred to as spacing learning paradigm [36]: a repeated presentation of the learning contents and a linked and repeated practice on test trials over a wide period [37].

The spacing learning and its effects were described for the first time in 1885 by Ebbinghaus [38]. He argued that "a considerable number of repetitions distributed over a space of time is decidedly more advantageous than the massing of them in a single time" [39]. Halpern et al. [37] suggest to conceive spacing learning and spaced learning practices as primary 'laws' that enhances long-term retention. It is a kind of multiple-trial learning that creates multiple traces of the same event in memory and increases knowledge retention [36]. Spacing learning (or spacing effect in learning) is one of the oldest and best-analyzed phenomena in the field of learning and memory research [39-41], but most research studies focus, as can also be seen from the descriptions above, on the learning of factual material, leaving aside the learning of high-level thinking skills [42]. In particular, very few studies have been carried out on the possible effects of spacing learning on the ability to think critically [4245]. Moreover, to the best of our knowledge, there are no studies on the relationship between spacing learning and critical thinking within a video-gaming context.

Finally, further studies are needed on further cognitive aspects involved in the specific context of serious gaming within a spacing learning approach. Such a methodology, defined as primary 'law' that enhances long-term retention, could deal with the role of working memory, long-term memory, and attention during the learning experience within serious games.

\section{$7 \quad$ References}

[1] H. S. Barrows, \& Tamblyn, R. M. . Problem-based learning: An approach to medical education. Springer Publishing Company, New York, 1980.

[2] M. Ebner, \& A. Holzinger, Successful implementation of user-centered game based learning in higher education: An example from civil engineering, Computer \& Education, Vol. 49, Nr. 3, pp. 873-890, 2007. https://doi.org/10.1016/j.compedu.2005.11.026

[3] S. Tang, M. Hanneghan, and A. El Rhalibi, "Introduction to games-based learning," in T. M. Connolly, M. H. Stansfield and E. Boyle (Eds.) Games-Based Learning Advancements for Multi-Sensory Human Computer Interfaces: Techniques and Effective Practices, US: IGI Global, 2009. 
[4] M. M. Ariffin, A. Oxley, and S. Sulaiman, Evaluating Game-based Learning Effectiveness in Higher Education, Procedia-Social and Behavioral Sciences, 123, 20-27, 2014.

[5] S. de Freitas, Learning in Immersive worlds A review of game-based learning, JISC e-Learning Innov, 3, 73. 2006.

[6] D. R. Michael, S. L. Chen, Serious games: games that educate, train, and inform. Thomson Course Technology PTR , Boston, MA, 2006. https://doi.org/10.1021/la104669k

[7] M. Qian and K. R. Clark, Game-based Learning and 21st century skills: A review of recent research, Computers in Human Behavior, 63: 50-58, 2016. https://doi.org/10.1016/j.chb.2016.05.023

[8] M. Romero, M. Usart, and M. Ott, Can serious games contribute to developing and sustaining 21st century skills?, Games and Culture. 10(2), 148-177, 2015. https://doi.org/10.1177/1555412014548919

[9] E. A. Boyle, E. W. MacArthur, T. M. Connolly, T. Hainey, M. Manea, A. Kärki, \& P. Van Rosmalen, A narrative literature review of games, animations and simulations to teach research methods and statistics, Computers \& Education, 74, 1-14, 2014. https://doi.org/10.1016/j.compedu.2014.01.004

[10]R. Berta, F. Bellotti, E. van der Spek, T. Winkler, A tangible serious game approach to Science, Technology, Engineering, and Mathematics (STEM) education. In: Nakatsu, R., Rauterberg, M., Ciancarini, P. (eds.) Handbook of Digital Games and Entertainment Technologies, pp. 571-592. Springer, Singapore, 2017. https://doi.org/10.1007/978-981-4560-50-4 32

[11] T. M. Connolly, E. A. Boyle, E. W. MacArthur, T. Hainey, J.M. Boyle, A systematic literature review of empirical evidence on computer games and serious games. Computers \& Education. 59(2), 661-686, 2012. https://doi.org/10.1016/j.compedu.2012.

[12] R. N. Van Eck, M. Guy, T. Young, A. T. Winger, and S. Brewster, Project NEO: A Video Game to Promote STEM Competency for Preservice Elementary Teachers, Technology, Knowledge and Learning, 20(3), 277-297, 2015. https://doi.org/10.1007/s10758-015-9245-9

[13]S. D McDonald, Enhanced Critical Thinking Skills through Problem-Solving Games in Secondary Schools, Interdisciplinary Journal of E-Learning \& Learning Objects, 13, 79-96, 2017. https://doi.org/10.28945/3711

[14] J. W. Smith and G. Clark, New Games, Different Rules Millennials Are In Town, Journal of Diversity Management (JDM), 5(3), 1-12, 2010. https://doi.org/10.19030/jdm.v5i3.810

[15] W. H. Wu, W. Bin Chiou, H. Y. Kao, C. H. Alex Hu, and S. H. Huang, Re-exploring game-assisted learning research: The perspective of learning theoretical bases,Computers \& Education, 59(4), 11531161, 2012. https://doi.org/10.1016/j.compedu.2012.05.003

[16] J. J. Vogel, D. S. Vogel, J. Cannon-Bowers, G. A. Bowers, K. Muse, and M. Wright, Computer gaming and interactive simulations for learning: A meta-analysis, Journal of Educational Computing Research, 34(3), 229-243, 2006. https://doi.org/10.2190/FLHV-K4WA-WPVQ-H0YM

[17] C. Dede, "Comparing frameworks for 21 st century skills. In J. Bellance, \& R. Brandt (Eds.), 21st century skills: Rethinking how students learn (pp. 51-76). Bloomington, IN: Solution Tree Press, 2010.

[18] B. Trilling,\& C. Fadel, 21st century skills: Learning for life in our times. San Francisco, CA, US: JosseyBass, 2009..

[19] M. Akcaoglu and M. J. Koehler, Cognitive outcomes from the Game-Design and Learning (GDL) afterschool program, Computers \& Education, 75, 72-81, 2014. https://doi.org/10.1016/j.compedu.2014.02.003

[20] N. Vos, H. Van Der Meijden, and E. Denessen, Effects of constructing versus playing an educational game on student motivation and deep learning strategy use, Computers \& Education, 56(1), 127-137, 2011. https://doi.org/10.1016/j.compedu.2010.08.013

[21] Y. T. C. Yang and C. H. Chang, Empowering students through digital game authorship: Enhancing concentration, critical thinking, and academic achievement, Computers \& Education, 68, 334-344, 2013. https://doi.org/10.1016/j.compedu.2013.05.023

[22] Y. T. C. Yang and W. C. I. Wu, Digital storytelling for enhancing student academic achievement, critical thinking.; Learning motivation: A year-long experimental study, Computers \& Education, 59(2), 339-352, 2012. https://doi.org/10.1016/j.compedu.2011.12.012

[23] Y. T. C. Yang, Building virtual cities, inspiring intelligent citizens: Digital games for developing students' problem solving and learning motivation, Computers \& Education, 59(2), 365-377, 2012. https://doi.org/10.1016/j.compedu.2012.01.012

[24]P. A. Facione, Critical Thinking : A Statement of Expert Consensus for Purposes of Educational Assessment and Instruction, American Philosophical Association, Delphi Res. Rep., Newark, DE, 1990.

[25] L. F. Zhang, Contributions of thinking styles to critical thinking dispositions. The Journal of Psychology, Vol. 137, Nr. 6, pp. 517-544, 2003. https://doi.org/10.1080/00223980309600633 
[26]E. Glaser, An Experiment in Development of Critical Thinking. Teachers Collage Record, Columbia University, 1941.

[27]H. E. Kiliç, \& A. I. Sen, Turkish adaptation study of UF/EMI critical thinking disposition instrument. Education and Science, Vol. 39, Nr. 176, pp. 1-12, 2014. DOI: 10.15390/EB.2014.3632

[28] R. Paul, J. A. Binker, K. Jensen, \& H. Krelau, Critical Thinking Handbook: K-3rd Grades. A Guide for Remodelling Lesson Plans in Language Arts. Social Studies and Science. Rohnert Park, CA, 1990.

[29] M. Gentile, G. Città, S. Perna, A. Signa, F. Reale, V. Dal Grande, S. Ottaviano, D. La Guardia, \& M. Allegra, "The Effect of Disposition to Critical Thinking on Playing Serious Games", In M. Gentile, M. Allegra, H. Söbke (Eds.), Games and Learning Alliance. GALA 2018. Lecture Notes in Computer Science, vol 11385. Springer, Cham, 2019. https://doi.org/10.1007/978-3-030-11548-7_1

[30] N. Krueger, Entrepreneurial education in practice-part 1 the entrepreneurial mindset. Paris: OCDE, 2015.

[31]R. Bell, \& M. Loon, The impact of critical thinking disposition on learning using business simulations. The International Journal of Management Education, Vol. 13, Nr. 2, pp. 119-127, 2015. https://doi.org/10.1016/j.ijme.2015.01.002

[32] R Core Team, R: A Language and Environment for Statistical Computing. Vienna: R Foundation for Statistical Computing. 2018

[33] Y. Rosseel. lavaan: an R package for structural equation modeling. Journal of Statistical Software. Vol. 48, Nr. 2, pp. 1-36, 2012. doi: 10.18637/jss.v048.i02

[34] J. B. Schreiber, A. Nora, F. K. Stage, E. A. Barlow, \& J. King, Reportig structural equation modeling and confirmatory factor analysis results : a Review. Journal of Educational Research, Vol. 99, Nr. 6, pp. 323338, 2006. https://doi.org/10.3200/JOER.99.6.323-338

[35] J. D. Karpicke, \& H. L. Roediger III, Repeated retrieval during learning is the key to long-term retention. Journal of Memory and Language, Vol. 57, Nr. 2, pp. 151-162, 2007. https://doi.org/10.1016/j.jml.2006.09.004

[36] D. F. Halpern, K. Millis, A. C. Graesser, H. Butler, C. Forsyth, \& Z. Cai, Operation ARA: A computerized learning game that teaches critical thinking and scientific reasoning. Thinking Skills and Creativity, Vol. 7, Nr. 2, pp. 93-100, 2012. https://doi.org/10.1016/j.tsc.2012.03.006

[37] C. Forsyth, A. Graesser, B. Walker, K. Millis, P.I. Pavlik, \& D. Halpern, "Didactic galactic: Types of knowledge learned in a serious game”. In H.C. Lane, K. Yacef, J. Mostow, and P. Pavlik (eds.) Artificial Intelligence in Education. AIED 2013. Lecture Notes in Computer Science, Vol. 7926. Springer, Berlin, Heidelberg, 2013. https://doi.org/10.1007/978-3-642-39112-5_124

[38] H. Ebbinghaus, Memory: A contribution to experimental psychology. Annals of neurosciences, Vol. 20, Nr. 4, pp. 155-156, 2013. doi: 10.5214/ans.0972.7531.200408

[39] R. L. Greene, Human memory: Paradigms and paradoxes. Psychology Press, Hillsdale, NJ, US: Lawrence Erlbaum Associates, Inc., 2014.

[40] J. D. Karpicke, \& A. Bauernschmidt, Spaced retrieval: absolute spacing enhances learning regardless of relative spacing. Journal of Experimental Psychology: Learning, Memory, and Cognition, Vol. 37, Nr. 5, pp. 1250-1257, 2011. http://dx.doi.org/10.1037/a0023436

[41]E. J. Fishman, L. Keller, \& R. C. Atkinson, Massed versus distributed practice in computerized spelling drills. Journal of educational psychology, Vol. 59, Nr. 4, pp. 290-296, 1968. http://dx.doi.org/10.1037/h0020055

[42] V. Foot-Seymour, J. Foot, \& M. Wiseheart, Judging credibility: Can spaced lessons help students think more critically online? Applied Cognitive Psychology, 2019. https://doi.org/10.1002/acp.3539

[43] I. V. Kapler, T. Weston, \& M. Wiseheart, Spacing in a simulated undergraduate classroom: Long-term benefits for factual and higher-level learning. Learning and Instruction, Vol. 36, pp. 38-45, 2015. https://doi.org/10.1016/j.learninstruc.2014.11.001

[44] M. Gluckman, H. A. Vlach, \& C. M, Sandhofer, Spacing simultaneously promotes multiple forms of learning in children's science curriculum. Applied Cognitive Psychology, Vol. 28, Nr. 2, pp. 266-273, 2014. https://doi.org/10.1002/acp.2997

[45]H. A. Vlach, \& C. M. Sandhofer, Distributing learning over time: The spacing effect in children's acquisition and generalization of science concepts. Child development, Vol. 83, Nr. 4, pp. 1137-1144, 2012. https://doi.org/10.1111/j.1467-8624.2012.01781.x 